\title{
EDITORIAL The Implementation of Composite Materials in Engineering Structures where Total Safety is of the Essence
}

\author{
P. W. R. Beaumont • Costas Soutis • Alma Hodzic
}

Received: 18 January 2012 / Accepted: 20 January 2012 / Published online: 7 February 2012

(C) Springer Science+Business Media B.V. 2012

This issue is a compilation of selected papers presented at the International Conference on Deformation and Fracture (DFC-11) and Structural Integrity (SI-5), a combined meeting on Composite Materials held for the first time at Queens' College, Cambridge, England, 13-15th April, 2011.

Predicting precisely where a crack will develop in a material under stress and exactly when in time catastrophic fracture of the component will occur is one the oldest unsolved mysteries in the design and building of large-scale engineering structures. Where human life depends upon engineering ingenuity, in aircraft design for instance, the burden of testing to prove a "fracture safe design" is immense. When human life depends upon structural integrity as an essential design requirement, it takes thousands of material test coupons for every composite laminate configuration to evaluate an airframe plus loading to ultimate failure tails, wing boxes, and fuselages to achieve airworthiness certification.

Fitness considerations for long-life implementation of critical load-carrying components in aerospace structures, for example, include, on the one hand, understanding deformation and fracture phenomena resulting from impact, fatigue, creep, and stress corrosion cracking. Structural integrity analysis, on the other, treats the design, the materials used, and figures out how best components and parts can be joined, while taking into account reliability, life expectancy, and durability of structure in service. However, there are conflicting aims in the complete "cradle to grave" process of designing simultaneously for high efficiency and safety assurance throughout an economically viable lifetime with an acceptable level of risk.

For two decades, the Deformation and Fracture of Composites (DFC) conference series of Sheffield University has provided an international forum for the discussion of critical engineering issues and impact of composite materials on different industry sectors. Likewise, Cambridge University has provided the stage to present ideas on the Structural Integrity (SI) of composite materials and structures at bi-annual meetings held in Cambridge

P. W. R. Beaumont $(\square)$

University of Cambridge, Cambridge, UK

e-mail: pwrb@eng.cam.ac.uk

C. Soutis · A. Hodzic

University of Sheffield, Sheffield, UK 
and touring world wide: meetings of Capri, Monterey, and Madeira have all focused on solving problems by multi-scale modelling of the deformation and fracture of composite structures from the very small to the very large.

This particular combined Sheffield-Cambridge Conference embraced contributions from materials science and engineering, fabrication and processing technology, non-destructive inspection (NDI) and ND evaluation (NDE), and throughout service health monitoring of structure (SHM) and safety management across a broad spectrum of size scale. Now a combination of interacting factors demanded consideration: the criticality of the application; the accessibility for and ability to inspect vital parts and components; the intended use including load spectrum and time; the consequences of impact, fatigue, environment, and temperature; the manufacturing technique and inherent flaws and their detection.

A major aim of the Meeting at Cambridge was to facilitate scientific and technological interaction between the best composite materials scientists and engineers world-wide; to coordinate an inter-disciplinary effort on fundamental issues and practical problems that affect the development and exploitation of large composite structures; and to transfer ideas from the research and development stage to the design engineer and end-user of the composite material.

It was a problem driven conference that focused on the nature of the engineering problem; the fundamental understanding of the material at the nano and microscopic scale; how to design the micro-structural features that control the properties of material; and how to build into predictive design equations the functional behaviour of a large structure for a specific end-application.

First and foremost, we would like to acknowledge the generous financial support of the Office of Naval Research (ONR) and Air Force Office for Scientific Research \& Development (EOARD).

Likewise, The Institute of Materials, Minerals and Mining, The Royal Aeronautical Society, The Institution of Mechanical Engineers, the National Composites Network and the European Society of Composite Materials for their endorsement.

Finally, we thank the authors who submitted these papers, the international technical advisory committee and the referees who helped ensure that the previously set high standard of the Journal Applied Composite Materials (ACMa) has been maintained through publication of this collection of selected papers.

The Chairpersons:

Professor Costas Soutis and Dr Alma Hodzic, University of Sheffield, and Dr Peter Beaumont, University of Cambridge.

Cambridge, January, 2012 